The $B D J$ News section accepts items that include general news, latest research and diary events that interest our

readers. Press releases or articles may

be edited, and should include a colour

photograph if possible. Please direct your

correspondence to the News Editor,

Arveen Bajaj at the BDJ, The Macmillan

Building, 4 Crinan Street, London N1 9XW

or by email to bdj@bda.org

\section{New Masters course launched}

A new postgraduate degree course has been developed for experienced dentists at the University of Salford's School of Health Care Professions. Launched in September, the three year part-time Masters Programme in Dental Implantology is already fully subscribed.

The Salford Programme's 19 students will learn using a mixture of innovative methods of academic and clinical study as well as the University's Virtual Learning Environment.

In addition, the University has developed a new framework for the clinical training of dentists at their workplace under the supervision of experienced implantologists. The mentor training programme has already been successful and a further series of training days are planned for the next academic year at the School in collaboration with national implant organisations.

The programme's Clinical Lead, Cemal Ucer, said, 'Until recently formal education and training in implantology have lagged behind the rapid scientific advancements made in this field. This innovative and highly structured course, in collaboration with a German University, has been designed to provide internationally recognised high quality training for future dental implantologists in the UK.'

\section{New chair for ORE}

Professor Elizabeth Davenport has been appointed as Chair of a new GDC board to ensure the successful delivery of its new examination for overseas dentists applying to work in the UK - the Over-

\title{
Liverpool gets new dental training facility
}

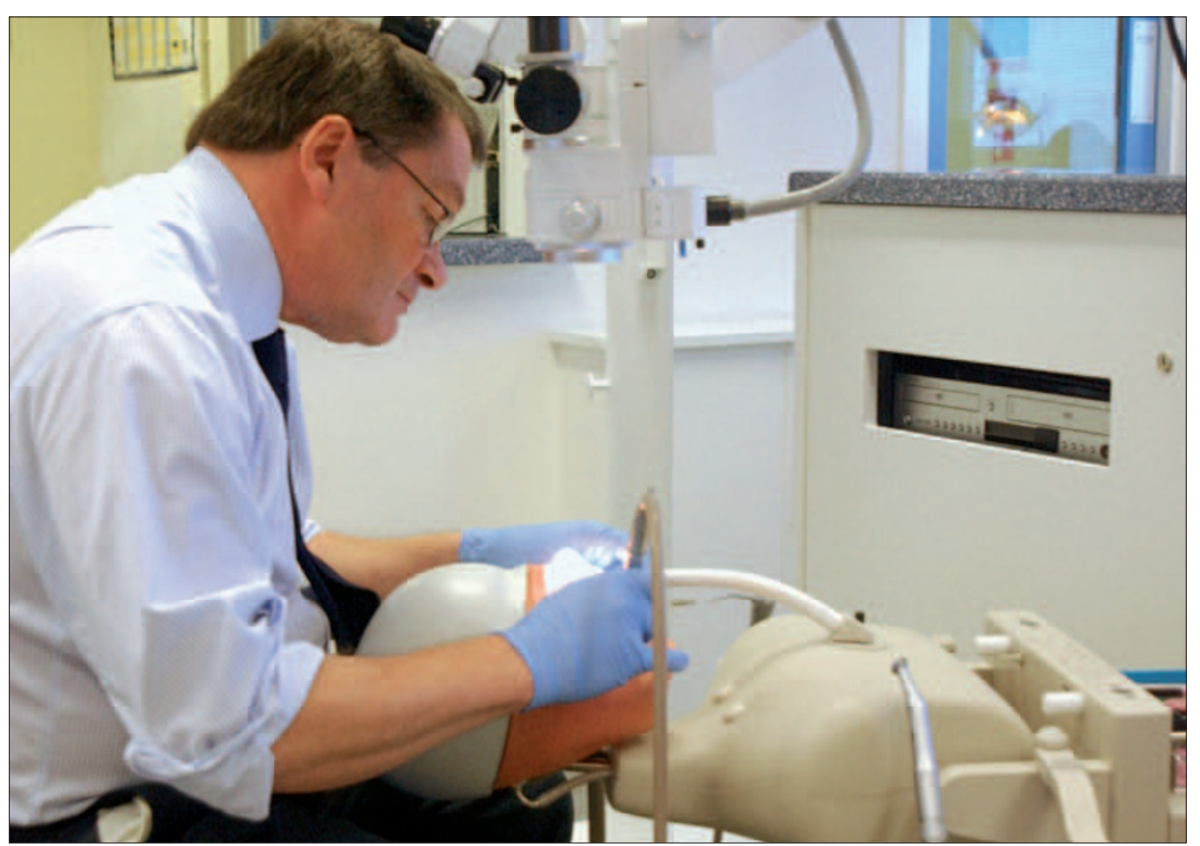

One of Europe's largest facilities for training dentists has opened in Liverpool, marking the start of a $£ 6$ million investment programme. The $£ 1.1$ million Operative Skills Suite at the University of Liverpool's Dental School features 46 'phantom heads' which enable dental students to develop clinical skills on a life-like replica of a human mouth. The state-of-the-art facility features digital $\mathrm{X}$-ray imaging connected to each unit so students can view clinical demonstrations as they learn. The opening of the suite by England's Chief Dental Officer Barry Cockroft is part of an investment by the Department of Health and the Higher Education Funding Council for England in enhanced teaching facilities in the School of Dentistry, which will enable an increase in student places from 275 to 400 by 2009 . The investment programme includes the construction of five sedation suites and five oral surgery suites, state-of-the-art training facilities, new tutorial rooms, enhanced patient facilities and new laboratories. A specialist unit for patients with disabilities will also be created. The unit has been specially designed to accommodate wheelchair users, with street level access and larger areas for administering treatment. Sedation and recovery facilities have also been designed for patients with special needs in mind.

seas Registration Examination (ORE).

She will now help establish and lead the Overseas Registration Examination Board (OREB), playing a key role in recruiting members of the Board. Professor Davenport was originally involved in the review of the International Qualify- ing Examination (the predecessor to the ORE) and the implementation of the ORE. She is Professor of Dental Education and Director of Quality with the Institute of Dentistry at Barts and The London Queen Mary's School of Medicine and Dentistry. 


\section{Campaign highlights dentistry access problems in England}

A new survey looking at access to dental care in England in the wake of the 2006 reforms to NHS dentistry has found that $78 \%$ of patients using private dental services are doing so either because their dentist stopped treating NHS patients, or because they could not find an NHS dentist.

The Dentistry Watch survey by the Commission for Public and Patient Involvement in Health (CPPIH) canvassed the views of 750 dentists and over 5,000 patients between July and September this year to assess the true state of the NHS dental system in England. It discovered widespread problems with access to NHS care, confusion about patient charges and patients resorting to self-treatment.

Results showed that 35\% of those not currently using dental services were doing so because there was not an NHS dentist near where they lived, 6\% said they had treated themselves, including extracting their own teeth because they were unable to get professional treatment and over half of all patients (and almost half of all NHS patients) did not understand dental charges.

Almost 20\% of NHS patients surveyed had gone without treatment because of was provided. get an NHS dental appointment. treatment the most. just cannot find a local NHS dentist.' anxieties about the charging system. the cost, although of the patients that did receive NHS treatment, almost all (93\%) were happy with the treatment that

Of the dentists surveyed, 45\% were not accepting any more NHS patients, 58\% believed that the quality of care patients received since the new dental contract had got worse and $84 \%$ of dentists believed that the new dental contract had failed in making it easier for patients to

Many dentists also reported unhappiness with the new contract, claiming that it offered them no incentive to take on new patients, was too target driven and penalised those who needed

Sharon Grant, Chair of the CPPIH commented, 'It appears many patients are being forced to go private because they do not want to lose their current trusted and respected dentist or because they

Responding to the results of the survey, BDA Executive Board Chair Susie Sanderson said that the survey painted an all-too-familiar picture of patients unable to access care, dentists struggling with a target driven system and

\section{Undergraduate prize awarded}

Final year BDS student Arthif Danial has been awarded the Frank Ashley Undergraduate Prize for the project Periodontal disease and diabetes: a dental elective study based in the Kingdom of Saudi Arabia.

The BSP Frank Ashley Undergraduate Award is named in memory of Professor Frank Ashley, a former President of the Society, and aims to encourage dental undergraduates to carry out projects related to periodontology, including electives. Mr Danial will be given a cheque for $£ 500$ to fund his elective trip.

He said, 'I was very much inspired by having done some research work in my intercalated BSc year and especially after having discussed the prospects of my elective period with my mentor Dr Mark Ide. This opportunity has now allowed me to view dentistry from another dimension.'

Applications are invited from stu- dents at UK dental schools and from graduates who have qualified within the previous twelve months. Joint entries are not acceptable for this award.

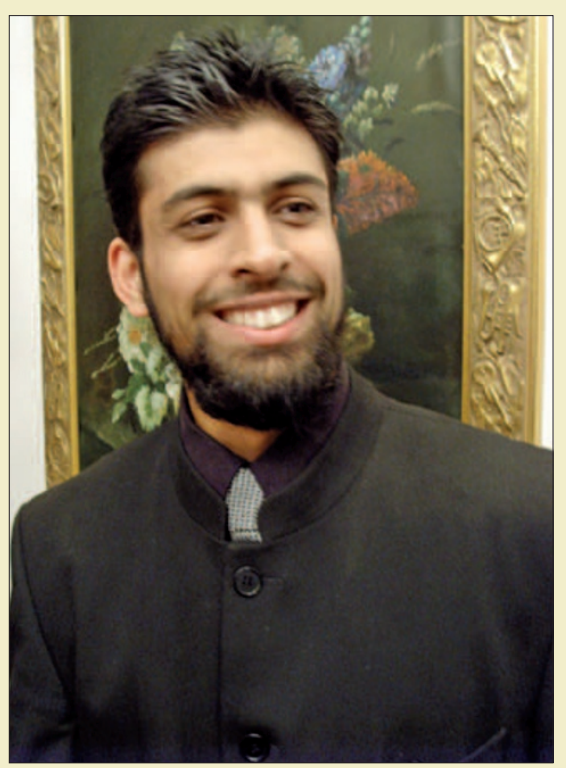

New President installed

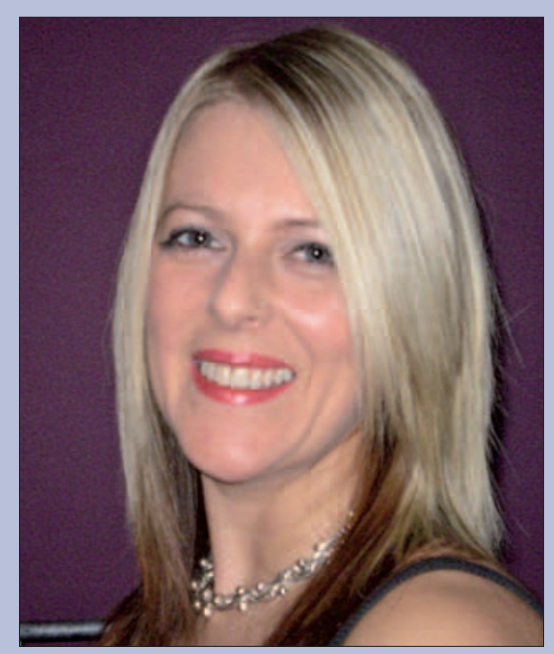

Angie McBain was installed as President of the British Association of Dental Nurses (BADN) at its annual conference this month. Having joined BADN in 1987, she founded its Bedford Local Group and has been on its Council since 2002, as the London \& South East Regional Coordinator, Finance Officer and President-elect, and on the BADN Finance Committee since 2004.

She currently works as the Lead Dental Nurse Tutor at Barnfield College, Luton where she has developed new dental nurse education programmes including a Dental Nurse Cadet Programme and a Foundation Degree in Dental Nursing.

\section{Endodontics focus}

The latest techniques in root-canal therapy are the focus of a new programme available at the University of Chester. The Postgraduate Certificate in Endodontics will provide in-depth training to existing dentists who wish to further their understanding in this area.

Programme Leader Dr Mike Horrocks, explained, 'Typically the undergraduate training is taught at a basic level with very little focus on contemporary endodontic techniques. Many dentists are very enthusiastic to enhance their competency in providing endodontic care to patients, signaling an increasing demand for postgraduate training programmes.'

Operating on a part-time basis over one year, the programme is divided into practical work, which will be carried out the in the student's surgery, and theoretical work. 


\section{Africa to integrate oral health into programmes}

Africa will be the first region of the world to take tangible action in integrating oral health into other chronic disease programmes, according to an expert consultation organised by the WHO Regional Office for Africa recently.

The meeting in Harare, Zimbabwe was attended by more than 20 participants including Chief Dental Officers from the African Region and experts from WHO Collaboration Centres, the FDI World Dental Federation and WHO Headquarters.

The experts discussed possibilities of implementing integrated activities in the context of child and maternal health, integrated management of childhood illness, school health, HIV/AIDS, traditional medicine, nutrition programmes and health education. They also outlined the need to propose guidelines for an integrated approach to oral health based on concrete actions to assist member states in implementing the May 2007 World Health Assembly resolution on oral health.

Dr Habib Benzian, Development and Public Health Manager of the FDI World Dental Federation said, 'Health professionals will be at the centre of an integrated approach to oral health. There is a need for constant dialogue between dental professionals and their colleagues in the fields of nursing, pharmacy, medicine and community health. Only by working together can true integration, based on the concept and understanding of common risks, become a reality'.

The recommendation of the expert consultation will form the basis of a report on the integrated approach to oral health that will be discussed at the 58th session of the WHO Regional Committee for Africa, to be held from 1 to 5 September 2008 in Cameroon.

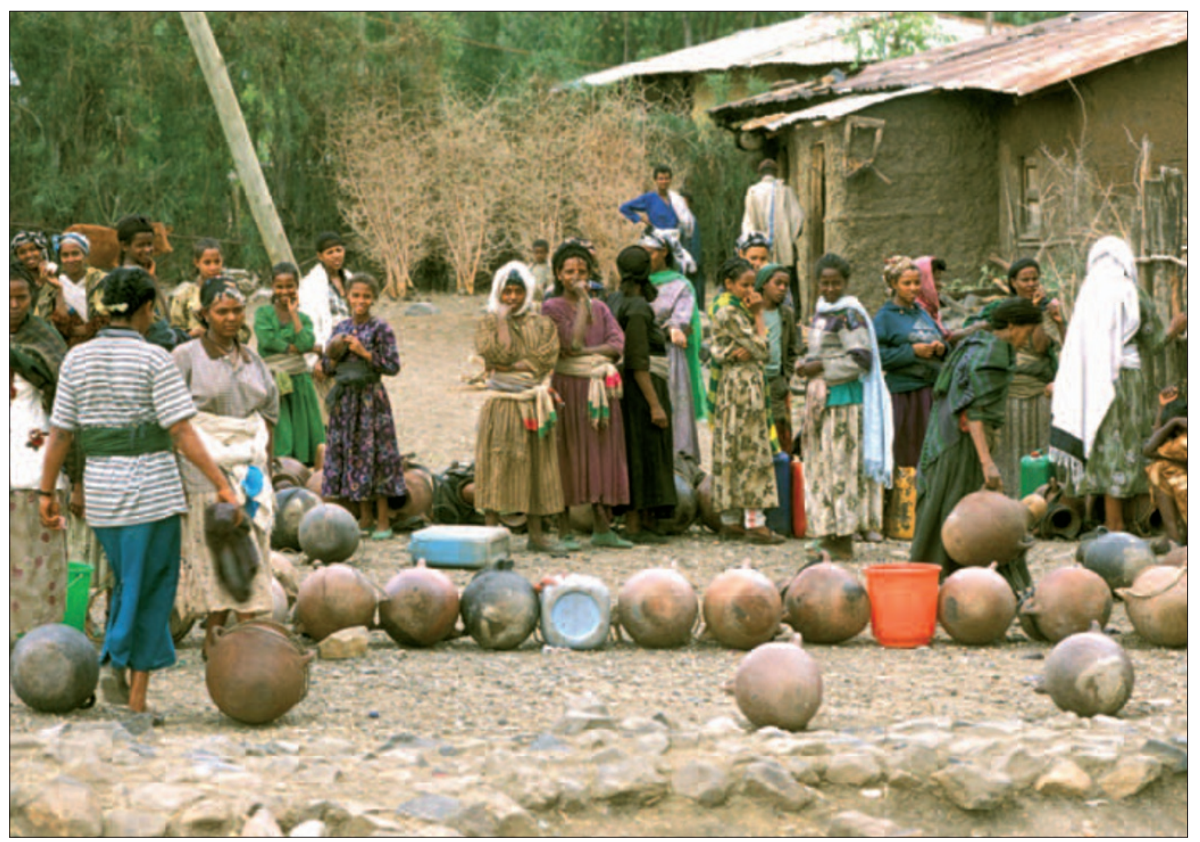

\section{Queen's dentist gets knighthood}

Mr Nicholas Sturridge was received by The Queen recently upon his retirement as Surgeon-Dentist to Her Majesty after many years. The honour of Knighthood was conferred upon him and he was invested with the insignia of a Knight Commander of the Royal Victorian Order. Sir Nicholas continues to work in his central London practice with his daughter, Dr Celine Sturridge.

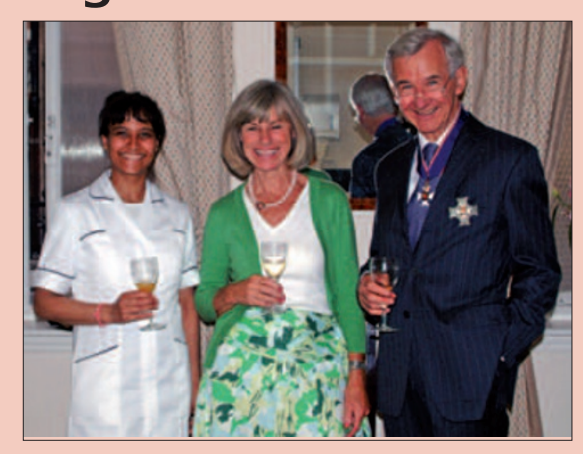




\section{DIARY}

November

University of Victoria's Annual Current Concepts in Dentistry Date: 10-13 November 2007 Venue: Victoria, British Columbia, Canada Tel: +1 (250) 721-4747

Email: register@uvcs.uvic.ca www.continuingstudies.uvic.ca/dental

East Lancashire \&t East Cheshire BDA Branch Dinner/Dance Date: 10 November 2007

Venue: Victoria \&t Albert Marriott Hotel, Water Street, Manchester

Tel: 07815088816

Email: derbylm@hotmail.com

BACD Fourth Annual Conference

Date: 15-17 November 2007

Venue: Novotel London West,

Hammersmith, London

Email: suzy@bacd.com

www.bacd.com

2nd International Conference on Evidence-based Advanced Dentistry and Silver Jubilee Celebrations of the Faculty of Dentistry, The University of Hong Kong Date: 16-19 Nov 2007

Venue: Hong Kong Academy of Medicine Email:dent25cb@hku.hk

www.dent25.hku.hk

The Dental Pan-Society

Conference 2007

Date: 16-17 November 2007

Venue: International Convention Centre,

Birmingham

Tel: 01494581526

Emailadmin@pandental2007.org

www.pandental2007.org

Portuguese Dental Association

Annual Meeting

Date: 22-24 November 2007

Venue: Lisbon Conference Centre,

Portugal

Email ordem@omd.pt

www.omd.pt

\section{December}

Seventh Annual Premier Symposium Date: Saturday 1 December 2007

Venue: Kings College,

London Waterloo campus

Email: sarah.cunliffe@mps.org.uk

www.dentalprotection.org

\section{Help the homeless this Christmas by volunteering}

Dentists are urgently needed to volunteer their services and help homeless people in London over the festive season as part of Crisis Open Christmas (COC) which runs from December 23-30.

The dental checks will be an integral part of the medical services on offer for homeless people in the capital, many of whom may not have received professional dental care for some time.

Eight temporary centres will be set up in London by Crisis, the national homeless charity, as part of the COC event. The centres will provide vital companionship and hot meals for many homeless and vulnerably housed people as well as essential services like health checks including dental care, housing advice, training and further education opportunities.
The COC dental service relies on qualified volunteer dentists to provide a range of routine dental treatments including checkups, scale and polishes, fillings and extractions under local anaesthetic. Volunteers may also need to give basic dental health advice and education.

Dental shifts are available from December 23 to 29 from 8.30am to $6 \mathrm{pm}$. Volunteer dentists are encouraged to do at least two shifts. Crisis hopes to build on the success of the COC campaign last year when 156 patients had dental treatment delivered by mobile units outside COC centres.

To find out more about volunteering as a dentist, call 0207426 3875, email volunteering@crisis.org.uk or apply online at www.crisis.org.uk/volunteering.

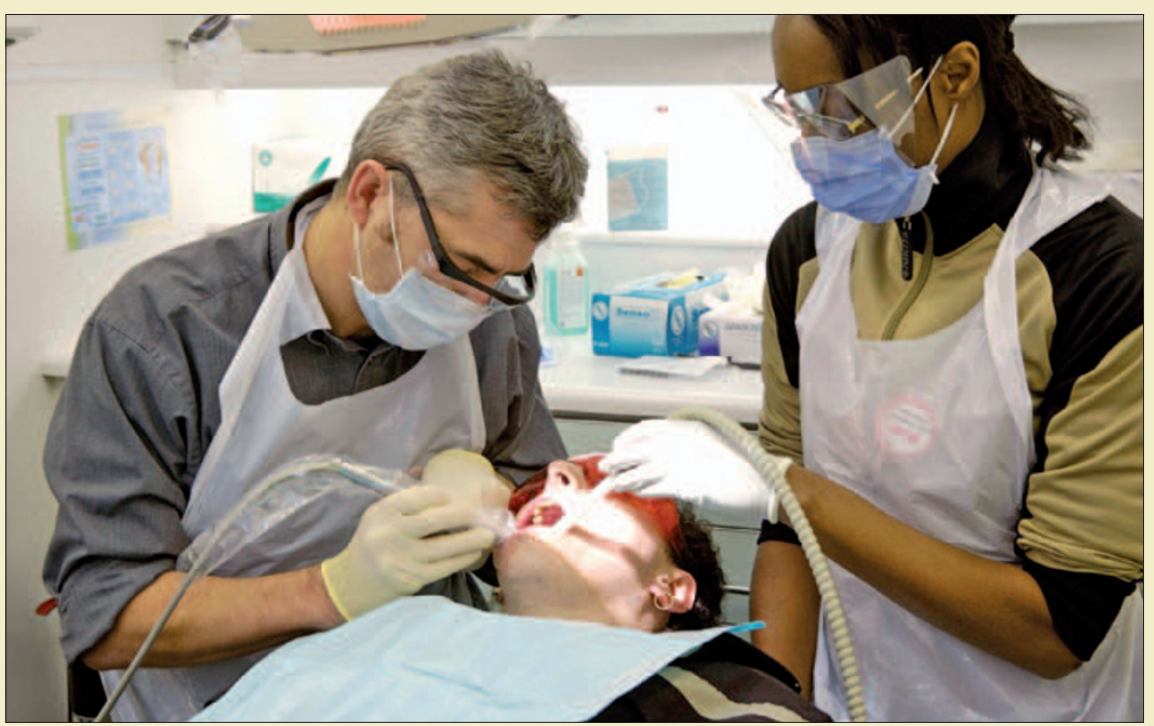

\section{Nun study links dementia and tooth loss}

Tooth loss may predict the development of dementia late in life, according to new research. Scientists from the University of Kentucky College of Medicine and College of Dentistry, Lexington, USA, studied data from 144 participants in the Nun Study, a study of ageing and Alzheimer's disease among Catholic sisters of the School Sisters of Notre Dame.

The researchers used dental records and results of annual cognitive examinations to study participants from the order's Milwaukee province who were 75 to 98 years old. The authors found that of the participants who did not have demen- tia at the first examination, those with few teeth (zero to nine) had an increased risk of developing dementia during the study compared with those who had ten or more teeth.

They proposed several possible reasons for the association between tooth loss and dementia: not only periodontal disease but also early-life nutritional deficiencies, infections or chronic diseases that may result simultaneously in tooth loss and damage to the brain. The study was published in the Journal of the American Dental Association (2007; 138: 1314-1322). 